\title{
Article \\ Evaluation of the Surface Defects and Dimensional Tolerances in Multi-Hole Drilling of AA5083, AA6061, and AA2024
}

\author{
Muhammad Aamir 1,*(D), Majid Tolouei-Rad ${ }^{1}$, Khaled Giasin ${ }^{2} \mathbb{D}$, Ana Vafadar ${ }^{1} \mathbb{D}$, Ugur Koklu $^{3}$ \\ and William Keeble ${ }^{2}$
}

Citation: Aamir, M.; Tolouei-Rad, M.; Giasin, K.; Vafadar, A.; Koklu, U.; Keeble, W. Evaluation of the Surface Defects and Dimensional Tolerances in Multi-Hole Drilling of AA5083, AA6061, and AA2024. Appl. Sci. 2021, 11, 4285. https://doi.org/10.3390/ app11094285

Academic Editor: Laurens Katgerman

Received: 13 April 2021

Accepted: 6 May 2021

Published: 10 May 2021

Publisher's Note: MDPI stays neutral with regard to jurisdictional claims in published maps and institutional affiliations.

Copyright: (c) 2021 by the authors. Licensee MDPI, Basel, Switzerland. This article is an open access article distributed under the terms and conditions of the Creative Commons Attribution (CC BY) license (https:/ / creativecommons.org/licenses/by/ $4.0 /)$.
1 School of Engineering, Edith Cowan University, Joondalup, WA 6027, Australia; m.rad@ecu.edu.au (M.T.-R.); a.vafadarshamasbi@ecu.edu.au (A.V.)

2 School of Mechanical and Design Engineering, University of Portsmouth, Portsmouth PO1 3DJ, UK; khaled.giasin@port.ac.uk (K.G.); William.keeble@port.ac.uk (W.K.)

3 Department of Mechanical Engineering, Faculty of Engineering, Karamanoglu Mehmetbey University, 70100 Karaman, Turkey; ugurkoklu@kmu.edu.tr

* Correspondence: m.aamir@ecu.edu.au

\begin{abstract}
Drilling is one of the most performed machining operations for riveting and assembly operations in many industrial sectors. The accuracy of the drilled holes and their surface finish play a vital role in the longevity and performance of the machined components, which, in turn, increase productivity. Therefore, this study investigated the effect of the multi-spindle drilling process on dimensional hole tolerances, such as hole size, circularity, cylindricity, and perpendicularity. In addition, the surface defects formed in the holes were examined using scanning electron microscopy. Three aluminium alloys, AA2024, AA6061, and AA5083, which are commonly used in the aerospace, automotive, and marine sectors, were chosen as the study materials. The results showed that the holes drilled in AA2024 gave less circularity error, cylindricity error, and perpendicularity error. In the case of hole size, the holes drilled in AA6061 were less deviated from the nominal size following holes drilled in AA2024 and AA5083 alloys. Surface damage in the form of metal debris adhesion, smeared material, side flow, and feed marks was found on the inner hole surface. Holes drilled in AA5083 alloy had the worst surface finish and were the most oversized, which was associated with noticeable damage and deformations in their inner surface. The ANOVA results revealed that the spindle speed was more influential than feed and mainly affected the hole size and cylindricity errors. However, in the case of circularity error and perpendicularity error, drilling parameters were found to be insignificant.
\end{abstract}

Keywords: multi-spindle drilling; aluminium alloys; surface defects; hole size; circularity; perpendicularity; cylindricity

\section{Introduction}

The success of many manufacturing operations depends upon proper planning and implementation of drilling operations. The drilling process depends on the properties of the workpiece, cutting parameters such as cutting speed and feed rate, and the type of materials and coatings used for the tools to obtain high-quality holes [1,2]. High-quality holes can reduce the chance of crack formation due to fatigue [3], thus avoiding about $60 \%$ of all part rejection in the final assembly [4]. Poor hole quality increases inspection time, which leads to costly corrective manufacturing measures [5]. Therefore, it is essential to assess the surface finish, circularity error, formation of burrs around the hole edges, deviation from hole size, cylindricity, and perpendicularity, which are the essential characteristics of hole-quality for tight geometric tolerances [6].

Aluminium and its alloys are widely used in various industries. Depending upon the application, the drilling process is among the most crucial metal cutting processes when these industries require high-quality holes [7]. The surface quality of aluminium is 
also vital because aluminium has a modulus of elasticity that is one-third of other metals, especially compared to steels; therefore, more defects are expected in aluminium, making it challenging to hold dimensional tolerances [8]. This is either due to the soft nature of aluminium or, to a lesser extent, the presence of hard particles in some of its alloys, which sticks onto the tool and results in the formation of built-up edges and associated high surface roughness [1]. Furthermore, during dry drilling of aluminium alloys, there might be more friction and heat generation where the hot chips clog the flutes, thus making the hole boundaries vulnerable due to temperature increases. Consequently, alloys with a high coefficient of thermal expansion can experience greater thermal distortion, which could adversely impact hole quality [9].

Previously, some investigations were carried out to evaluate hole quality for various aluminium alloys, metals, and composite materials. For instance, Kurt et al. [7] recommended HSS-5\%Co for minimum hole deviations during the one-shot drilling process of AA2024. The influence of cutting parameters on the hole size was found to be minor. However, the circularity error and radial deviation increased with the increase in the cutting parameters. In another study by Kurt et al. [10], it was concluded that the diametric error was affected more by the feed rate, while the cutting speed had a high impact on surface roughness. The experimental analyses during the drilling of AA6061 by Kushnoore et al. [11] revealed that spindle speed and feed rate play a vital role in affecting the thrust force, torque, and circularity error. The high thrust force, torque, and circularity error were due to the high drill diameter, spindle speed, and feed rate. Furthermore, Uddin et al. [12] concluded that the maximum increase of axial force and torque was due to increased feed rate. Therefore, a low feed rate was recommended due to stable and jerk-free cutting in one-shot drilling of AA6061. Besides this, the roughness was minimally influenced by both spindle speed and feed rate. During the drilling of AA6061, Islam and Boswell [13] investigated the impact of drilling parameters and three cooling methods, such as flood drilling minimum quantity lubrication (MQL) drilling and cryogenic drilling on the surface roughness, circularity, and hole size. Their study concluded that the best results for the dimensional accuracy and surface roughness were achieved by MQL drilling. Cryogenic drilling produced the best circularity results; however, in terms of dimensional accuracy and surface roughness, it was the worst. Nouari et al. [14] concluded that good dimensional accuracy and low surface roughness of holes during drilling of AA2024 was possible using a high cutting speed, a low feed rate, and drill bits with high helix angles, large point angles, and clearance angles between $6^{\circ}$ and $8^{\circ}$.

The above literature shows that previous work was mostly based on the one-shot drilling process. Therefore, this study aimed to extend the fundamental knowledge of drilling operations using a multi-hole simultaneous drilling approach to improve productivity and hole quality. Productivity and quality largely depend on the growth of any manufacturing industry [15]. Therefore, multi-spindle drilling is useful in industries where holes are required for mass production. In our previous research, the analysis of thrust force, assessment of hole quality in terms of surface roughness and formation burrs, chips analysis, and post-machining tool conditions were all investigated during multi-hole simultaneous drilling of AA5083, AA6061, and AA2024 [16]. This work was carried out to examine the influence of cutting parameters and workpiece materials on the important aspects of hole quality, such as hole deviation, circularity error, cylindricity, and perpendicularity. Additionally, this study examined the machined hole surface quality of AA5083, AA6061, and AA2024 using scan electron microscopy. Therefore, this study was conducted to compare the hole quality produced in different aluminium alloys and introduced the multi-spindle drilling process for high-quality holes to improve productivity.

\section{Materials and Methods}

The alloys of aluminium used in this study were AA5083, AA6061, and AA2024, which are the commonly used alloys in automotive, marine, and aerospace industries, 
respectively [16]. The chemical compositions in wt.\% and the properties of aluminium alloys studied in this work are given in Table 1.

Table 1. Details of aluminium alloys used in the current study [16].

\begin{tabular}{|c|c|c|c|c|c|c|c|}
\hline \multirow{2}{*}{ Element } & \multicolumn{3}{|c|}{ Composition in wt. $\%$} & \multirow{2}{*}{ Properties } & \multicolumn{3}{|c|}{ Aluminium Alloy } \\
\hline & AA2024 & AA6061 & AA5083 & & AA2024 & AA6061 & AA5083 \\
\hline $\mathrm{Mg}$ & $1.2-1.8$ & $0.8-1.2$ & $4.0-4.9$ & Machinability & $70 \%$ & $50 \%$ & $30 \%$ \\
\hline $\mathrm{Si}$ & 0.5 & $0.4-0.8$ & 0.4 & Shear strength (MPa) & 283 & 207 & 190 \\
\hline Mn & $0.3-0.9$ & 0.15 & $0.4-1.0$ & Ultimate tensile strength $(\mathrm{MPa})$ & 483 & 310 & 317 \\
\hline $\mathrm{Ti}$ & 0.15 & 0.15 & 0.15 & Hardness, Vickers & 137 & 107 & 96 \\
\hline $\mathrm{Zn}$ & 0.25 & 0.25 & 0.25 & Elongation at break & $18 \%$ & $12 \%$ & $16 \%$ \\
\hline $\mathrm{Cu}$ & $3.8-4.9$ & $0.15-0.4$ & 0.1 & Modulus of elasticity (GPa) & 73.1 & 68.9 & 71 \\
\hline $\mathrm{Fe}$ & 0.5 & 0.7 & 0.4 & Hardness, Brinell & 120 & 95 & 85 \\
\hline $\mathrm{Cr}$ & 0.1 & $0.04-0.35$ & $0.05-0.25$ & Thermal conductivity (W/m-K) & 121 & 167 & 117 \\
\hline $\mathrm{Al}$ & Balance & Balance & Balance & $\begin{array}{l}\text { The average coefficient of thermal } \\
\text { expansion (Coefficient from } 20 \text { to } \\
\left.100^{\circ} \mathrm{C}\right)\left(\mu \mathrm{m} / \mathrm{m}^{\circ}{ }^{\circ} \mathrm{C}\right)\end{array}$ & 23.2 & 23.6 & 23.75 \\
\hline
\end{tabular}

A manual milling machine model $(5 \mathrm{KS}, 5 \mathrm{KV})$ that has a maximum spindle speed of $3450 \mathrm{rpm}$ was used for the drilling operations, and a SUNHER poly-drill head type, $\mathrm{MH} 30 / 13$, was used for the multi-hole simultaneous drilling process. Spindle speeds of 1007,2015 , and $3025 \mathrm{rpm}$ and feeds of $0.04,0.08$, and $0.14 \mathrm{~mm} / \mathrm{rev}$ were selected based on the limitations of the available manual milling machine and previous literature on drilling aluminium alloys in the multi-spindle drilling process [16-20]. All the drilling experiments were conducted under dry conditions due to environmental concerns and the cost associated with the cutting fluid and its disposal [21,22]. The drill bits used were $6 \mathrm{~mm}$ twist drill uncoated carbide. The details of tool geometry are given in Table 2.

Table 2. Details of drill bits.

\begin{tabular}{cc}
\hline Specification/Description & \\
\hline Type & Twist drill \\
Material & Uncoated carbide \\
Number of flutes & 02 \\
Point angle & $140^{\circ}$ \\
Helix angle & $30^{\circ}$ \\
Drill diameter & $6 \mathrm{~mm}$ \\
\hline
\end{tabular}

The hole's geometrical tolerances, such as hole size, circularity, perpendicularity, and cylindricity, were measured at the top and the bottom of each hole using a coordinate measuring machine (CMM), type Mitutoyo Crysta-Apex S776, equipped with a Renishaw PH10MQ, fitted with an AM2 adjustment module and an SP25M scanning probe system as shown in Figure 1.

A $2 \mathrm{~mm}$ diameter ruby stylus was used for the measurements, first taking five points on the top surface of the sample to generate a base plane. Afterwards, three points were used to locate each hole before taking the geometric data by scanning the inside surface and taking points at a $0.1 \mathrm{~mm}$ pitch. A Gauss filter was applied to these points. Two measurement passes were performed inside each hole, $1 \mathrm{~mm}$ below the top surface of the sample and $1 \mathrm{~mm}$ above the bottom surface. With $\varnothing 6 \mathrm{~mm}$ holes, this resulted in between 95 and 97 points per measurement. Circles were generated from this data using the Maximum Inscribed Circle for each measurement. Roundness calculations were done internally by MCOSMOS. The hole size was also measured by scanning circles at the top and bottom of the bore with a $\varnothing 2 \mathrm{~mm}$ ruby stylus. Points were taken every $0.1 \mathrm{~mm}$, and the circle was calculated using the Maximum Inscribed Circle of the resulting point cloud, and the diameter of the circle was then taken. 


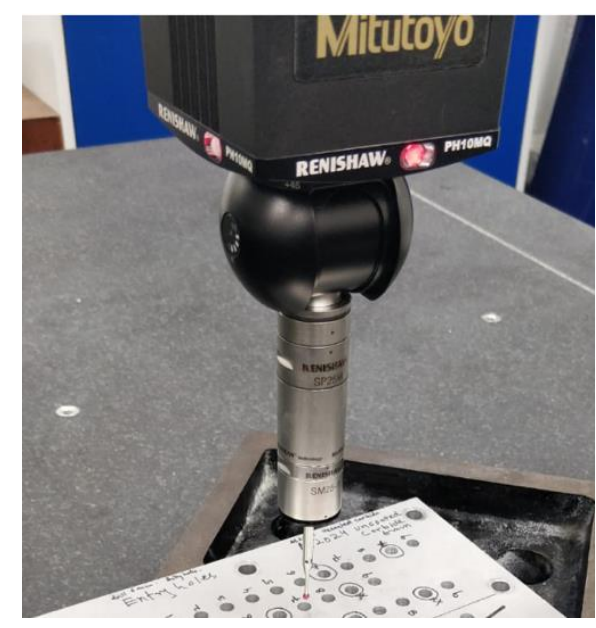

Figure 1. Hole geometry measurement setup using CMM.

The machined hole surface was examined using a scan electron microscopy (SEM) model, Hitachi SU5000. The holes were cut in half and examined under SEM to analyze the quality of the borehole surface. Finally, the analysis of variance (ANOVA) was employed on the studied hole quality parameters to determine the percentage contribution of the drilling parameters.

\section{Results}

\subsection{Analysis of Hole Size Analysis and Circularity Error}

The evaluation of hole size is one of the essential output parameters of the drilling process, especially during dry drilling, which is associated with higher cutting temperatures at the tool-chip interface due to increased friction and clogging of the chips over the flutes of drill bits [7]. Figure 2 shows the hole size of AA2024, AA6061, and AA5083 at different spindle speeds and feeds. The results showed that the holes obtained in AA6061 were less deviated from the nominal size than AA2024 or AA5083. The hole size for AA6061 ranged between 5.9990 and $5.9696 \mathrm{~mm}$, while this range increased to $6.0034-6.0863 \mathrm{~mm}$ for AA2024 and 6.0333-6.0941 mm for AA5083. Certain industries, such as aerospace industries, demand tight hole tolerances in metallic structures, as tight as \pm 12 microns and as relaxed as \pm 30 microns (H7 to $\mathrm{H} 9$ hole tolerance fit) [3]. Cutting tool manufacturers state that an acceptable hole size in aluminium alloys can range between \pm 20 and \pm 40 microns [23]. Other industries, such as in automotive industries, have more relaxed tolerances due to a less critical impact on the integrity of the vehicle structural components. This means that most of the hole size data reported in this study for AA2024 and AA6061 alloys fell within the limits of allowable hole tolerances in aerospace and automotive structures. For the AA5083 alloy, although not used in aerospace applications, it appears that the deviation in hole size exceeded the maximum recommended in aeronautical structures.

Similarly, hole size deviation in the AA6061 alloy reported in this study was significantly lower than that reported in a recent study [24]. The only difference in the tools used in both studies was that the previous study used coated tools (TiN, TiAlN, and TiN/TiAlN), while the current study used uncoated tools. The coating layer thickness, despite being less than several microns, might have had an impact on increasing the hole size deviation. Therefore, it can be said that drilling an AA6061 alloy using uncoated carbide drills might yield a hole size closer to the nominal drill diameter.

The results show that, in general, hole size tended to increase with the increase of the spindle speed $(n)$ and the feed $(f)$, especially for the AA6061 and AA5083 alloys. This could be attributed to the increased vibratory displacement with the increase of the $n$ and the $f$, which occurs during the initial contact between the chisel edge and the workpiece and triggers dynamic instability, causing higher hole size deviations [7,25]. However, it is evident from Table 3 that the impact of $f$ on the hole deviation was found to be insignificant, 
with a percentage contribution of $2.74 \%$. Overall, the hole deviation was affected more by the type of alloy, with a percentage contribution of $51.75 \%$. The influence of $n$ was found to be $9.71 \%$, while the two-way interaction of spindle speed and alloy type significantly impacted hole size with a contribution of $24.81 \%$.

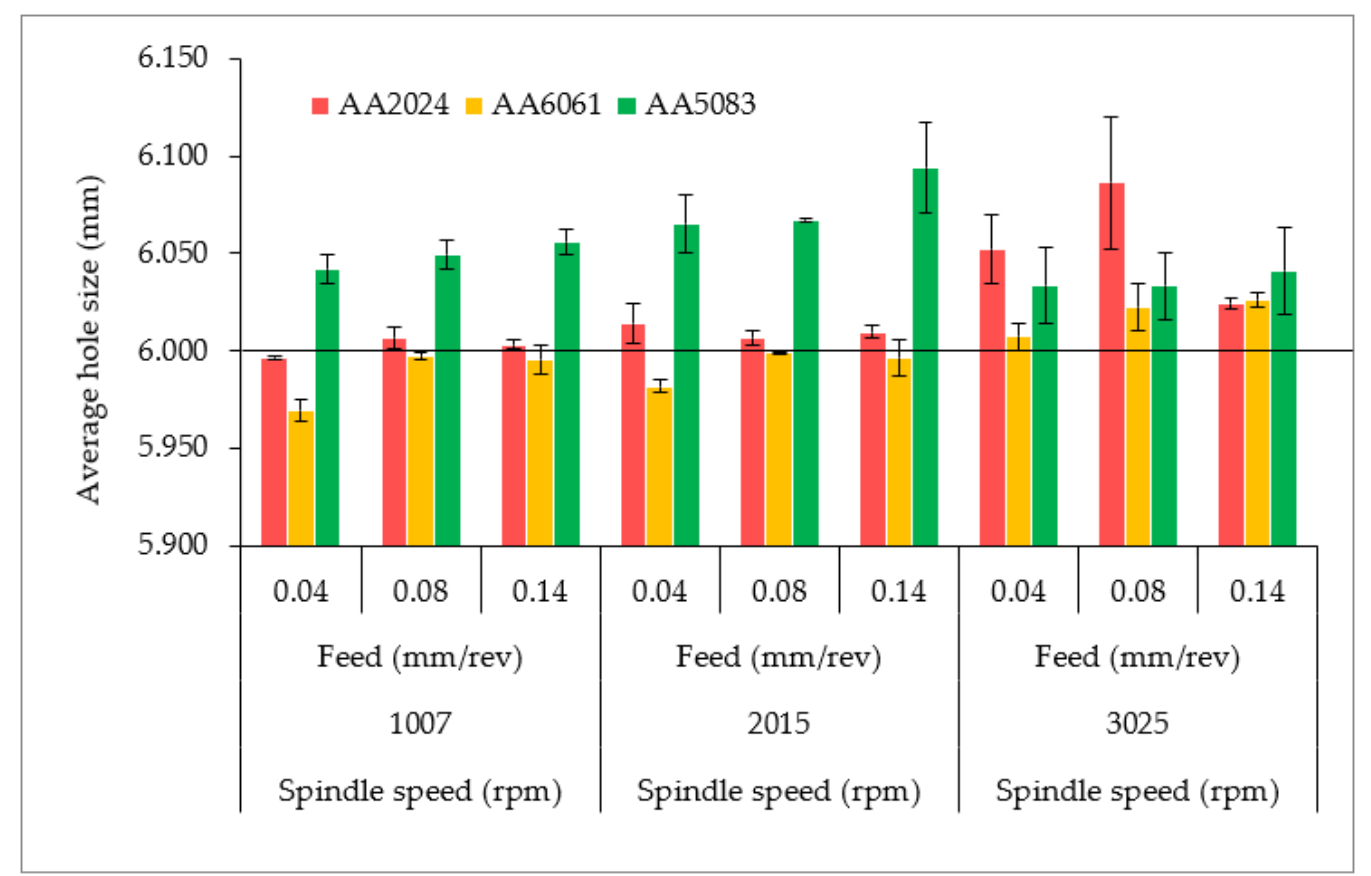

Figure 2. Effect of cutting parameters on hole size.

Table 3. Analysis of variance for hole quality metrics analyzed in the study.

\begin{tabular}{|c|c|c|c|c|c|c|c|c|}
\hline \multirow{2}{*}{ Source } & \multicolumn{2}{|c|}{ Hole Size } & \multicolumn{2}{|c|}{ Circularity } & \multicolumn{2}{|c|}{ Cylindricity } & \multicolumn{2}{|c|}{ Perpendicularity } \\
\hline & $p$-Value & Contribution & $p$-Value & Contribution & $p$-Value & Contribution & $p$-Value & Contribution \\
\hline Model & 0.001 & $96.08 \%$ & 0 & $97.06 \%$ & 0.024 & $90.24 \%$ & 0.009 & $92.60 \%$ \\
\hline Linear & 0 & $64.19 \%$ & 0 & $54.54 \%$ & 0.01 & $47.06 \%$ & 0.001 & $81.59 \%$ \\
\hline$n$ & 0.007 & $9.71 \%$ & 0.804 & $0.16 \%$ & 0.046 & $11.35 \%$ & 0.122 & $5.12 \%$ \\
\hline$f$ & 0.12 & $2.74 \%$ & 0.281 & $1.10 \%$ & 0.619 & $1.25 \%$ & 0.218 & $3.43 \%$ \\
\hline Alloy type & 0 & $51.75 \%$ & 0 & $53.28 \%$ & 0.002 & $34.46 \%$ & 0 & $73.04 \%$ \\
\hline 2-Way Interactions & 0.012 & $31.88 \%$ & 0.002 & $42.52 \%$ & 0.066 & $43.18 \%$ & 0.521 & $11.02 \%$ \\
\hline$n \times f$ & 0.386 & $2.33 \%$ & 0.389 & $1.73 \%$ & 0.218 & $8.89 \%$ & 0.779 & $1.61 \%$ \\
\hline$n \times$ Alloy type & 0.002 & $24.81 \%$ & 0 & $29.20 \%$ & 0.045 & $19.54 \%$ & 0.388 & $4.37 \%$ \\
\hline$f \times$ Alloy type & 0.134 & $4.74 \%$ & 0.007 & $11.59 \%$ & 0.086 & $14.75 \%$ & 0.328 & $5.04 \%$ \\
\hline Error & - & $3.92 \%$ & - & $2.94 \%$ & - & $9.76 \%$ & - & $7.40 \%$ \\
\hline Total & - & $100.00 \%$ & - & $100.00 \%$ & - & $100.00 \%$ & - & $100.00 \%$ \\
\hline
\end{tabular}

Figure 3 shows the circularity error of the hole at different drilling parameters during multi-hole simultaneous drilling for all the three alloys selected in this study. It is illustrated in Figure 3 that drilling in AA2024 showed less hole circularity error than AA5083 and AA6061 alloys, irrespective of the drilling parameters. AA5083 showed a higher circularity error than that obtained in the drilling of AA6061; however, at the $n$ of $3025 \mathrm{rpm}$, the circularity error increased compared to AA6061. This means that AA5083 performs better when machined at the lower $n$, while the AA6061 alloy shows lower hole circularity error when machined at a higher $n$. This could mainly be attributed to the higher magnesium content in the AA5083 alloy compared to the AA6061 alloy. Furthermore, adding magnesium to aluminium alloys contributes to maintaining a high degree of ductility/formability but is also known to be thermodynamically unstable at higher temperatures. This, in return, means that lower cutting parameters are more suited for softer aluminium alloys like AA5083 [26]. 


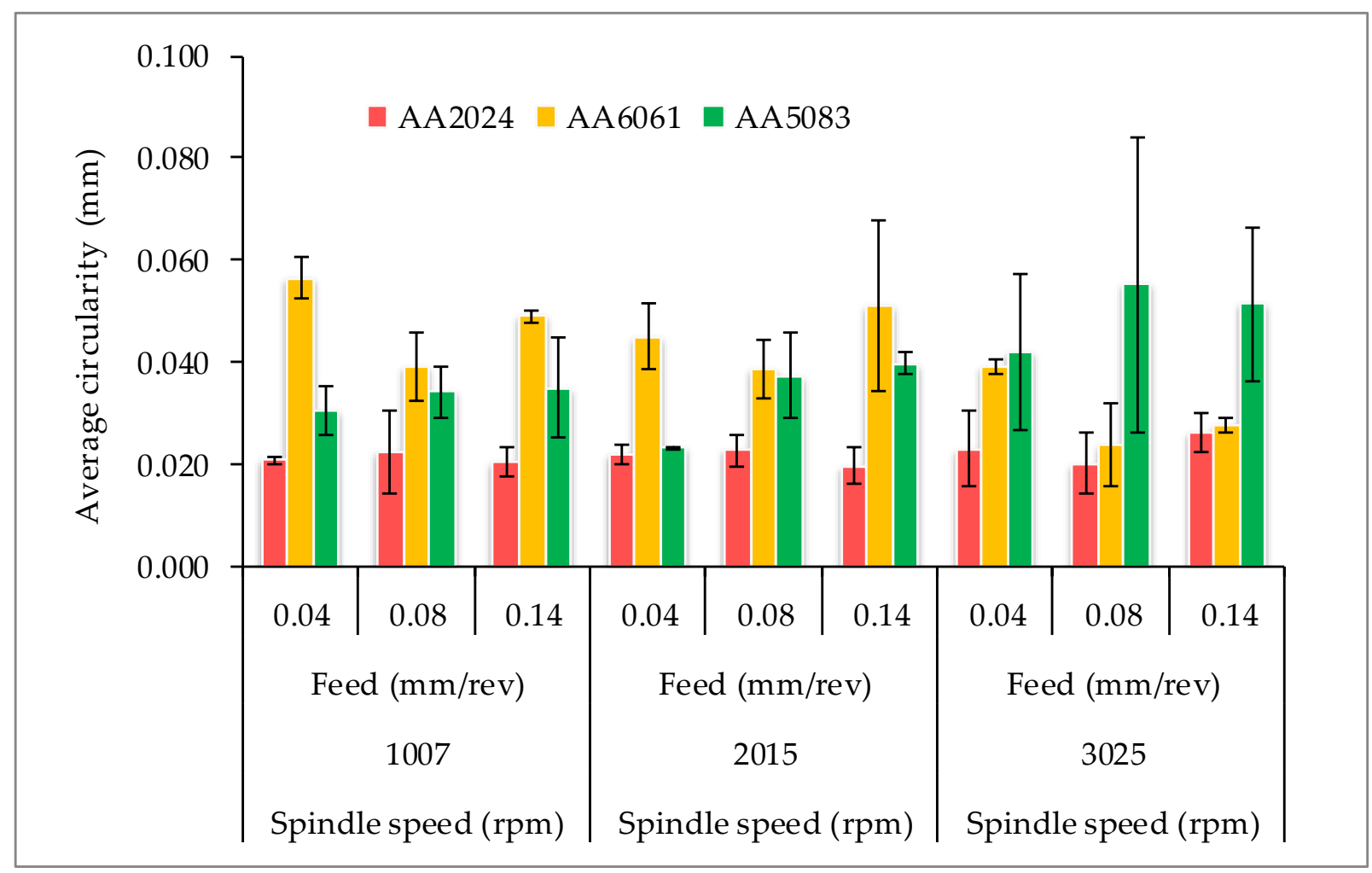

Figure 3. Effect of cutting parameters on hole circularity.

The minimum circularity error of $0.0197 \mathrm{~mm}$ was obtained for AA2024 at the $n$ of $2015 \mathrm{rpm}$ and $f$ of $0.14 \mathrm{~mm} / \mathrm{rev}$. For AA5083, the minimum circularity error was $0.0231 \mathrm{~mm}$, resulting from the $n$ of $2015 \mathrm{rpm}$ and $f$ of $0.04 \mathrm{~mm} / \mathrm{rev}$. Similarly, in the case of AA6061, the lowest circularity error was $0.0237 \mathrm{~mm}$ at the $n$ of $3025 \mathrm{rpm}$ and $f$ of $0.08 \mathrm{~mm} / \mathrm{rev}$. A comparison between the results reported in this study and previous studies $[24,25]$ on the same alloys and drill diameter, with the annotation that different feed rates, spindle speeds, tool geometry, and coatings were used, showed that hole circularity in AA2024 and AA6061 alloys was not critically influenced by the cutting tool coating or the level of cutting parameters. This conclusion is further supported by the ANOVA results shown in Table 3, which showed that both cutting parameters did not significantly affect hole circularity and displayed a non-linear trend at the circularity error, which could be confirmed by $p$-values of more than 0.05 . Table 3 also shows that alloy type was a significant factor of ANOVA. The alloy type had the highest contribution (53.28\%), followed by the interaction of the spindle speed and alloy type, which showed a contribution of $29.20 \%$ in affecting the circularity error.

\subsection{Hole Cylindricity and Perpendicularity}

Figure 4 shows the average values of hole cylindricity for AA2024, AA6061, and AA5083. The results showed that the lowest hole cylindricity error was possible when drilling AA2024, followed by AA6061 and then AA5083. The result showed that the lowest cylindricity error of $0.0240 \mathrm{~mm}$ was obtained during the drilling of AA2024, which was possible at the $n$ of $1007 \mathrm{rpm}$ and $f$ of $0.04 \mathrm{~mm} / \mathrm{rev}$. For AA6061, the minimum cylindricity error was $0.0389 \mathrm{~mm}$ and resulted at the $n$ of $3025 \mathrm{rpm}$ and $f$ of $0.08 \mathrm{~mm} / \mathrm{rev}$. The minimum hole cylindricity of $0.0403 \mathrm{~mm}$ for AA5083 was possible at the $n$ of $1007 \mathrm{rpm}$ and the $f$ of $0.04 \mathrm{~mm} / \mathrm{rev}$. These results agreed with the results obtained in the circularity error, where AA6061 showed the highest cylindricity error at low $n$. At the same time, AA5083 had the maximum cylindricity error at the highest $n$ of $3025 \mathrm{rpm}$, while a higher $n$ resulted in less circularity error for AA6061. Table 3 shows that the $n$ was somewhat influential on the cylindricity error with a percentage contribution of $11.35 \%$; however, the impact of feed 
and other interactions was insignificant. The most dominant factor in regard to cylindricity was the alloy type, with a percentage contribution of $34.46 \%$.

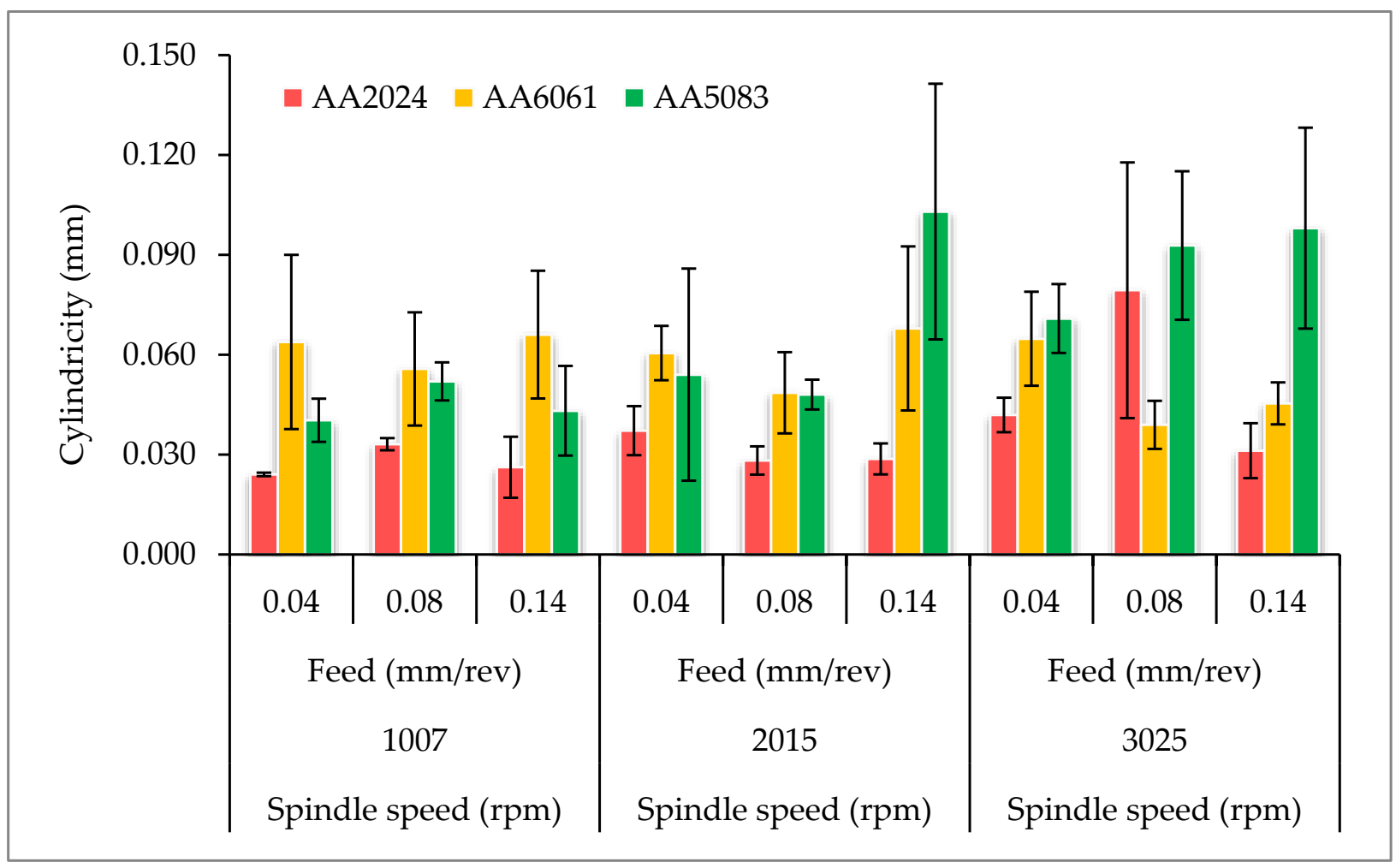

Figure 4. Effect of cutting parameters on hole cylindricity.

Similarly, the perpendicularity error for alloys selected in this study during multispindle simultaneous drilling is illustrated in Figure 5. Interestingly, the holes produced in AA2024 also gave the lowest perpendicularity, ranging between 0.0080 and $0.0178 \mathrm{~mm}$. AA5083 followed with minimum and maximum perpendicularity errors of 0.0222 and 0.0694, respectively. In contrast, AA6061 showed the maximum perpendicularity error, which ranged between 0.0331 and 0.0579 . The minimum value of the perpendicularity error for AA2024 was obtained at the $n$ of $3025 \mathrm{rpm}$ and $f$ of $0.08 \mathrm{~mm} / \mathrm{rev}$. In contrast, the same $f$ of $0.04 \mathrm{~mm} / \mathrm{rev}$ and spindle speeds of $1007 \mathrm{rpm}$ and $2017 \mathrm{rpm}$ caused the minimum perpendicularity for AA5083 and AA6061, respectively. However, like the cylindricity error, it was also evident from the ANOVA result that the only parameter that had the highest influence on the perpendicularity error was the alloy type, with a percentage contribution of $73.04 \%$, while none of the other parameters showed a significant impact on the perpendicularity error.

\subsection{Surface Damage Analysis}

Figure 6 shows SEM images of the inner borehole wall conditions of AA2024, AA6061, and AA5083 for holes drilled under dry conditions during the multi-spindle simultaneous drilling process. It was observed from the SEM micrographs that the damage and distortion found in the holes increased with the increase in spindle speed $(n)$ and the feed $(f)$. This is speculated to be due to the increase in vibration level, which influenced the geometrical hole tolerances. Additionally, it can be attributed to the increased thermal softening of the work material because of the rise in cutting temperatures with the increase of $n$ and deformations due to an increase in the $f$ [27]. 


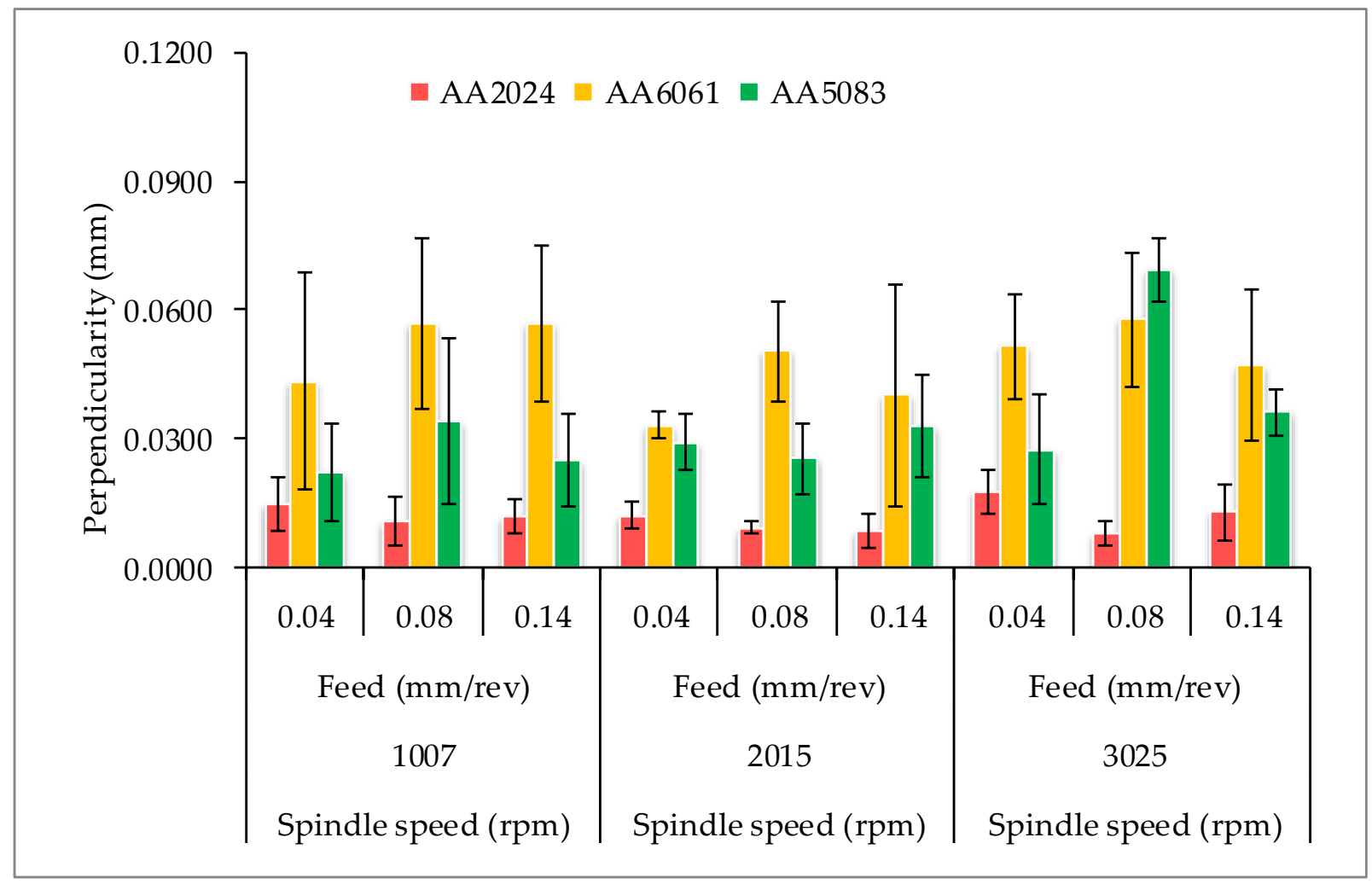

Figure 5. Effect of cutting parameters on hole perpendicularity.

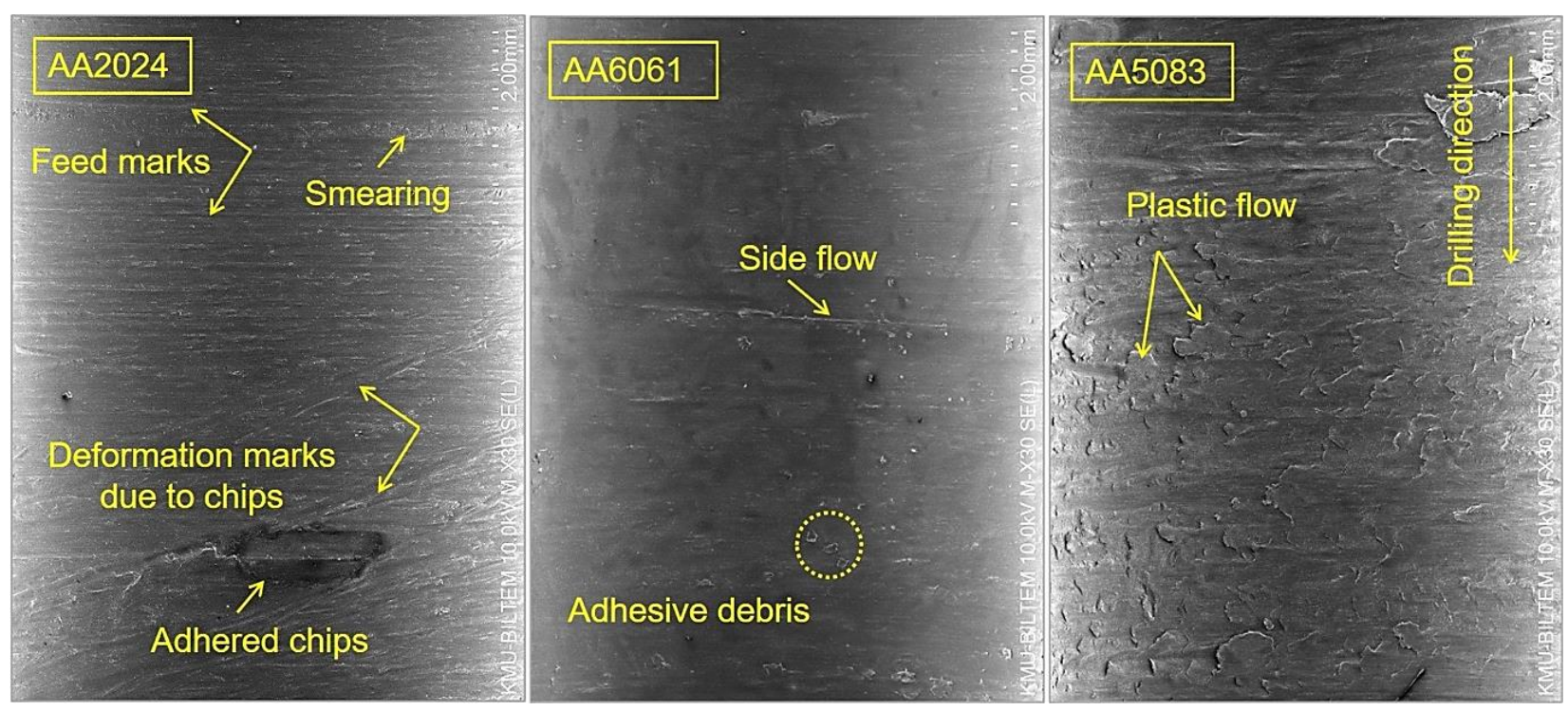

Figure 6. SEM of the hole drilled at $3025 \mathrm{rpm}$ and $0.14 \mathrm{~mm} / \mathrm{rev}$.

Figure 6 also revealed the formation of feed marks, deformation marks due to chips evacuation, adhesive debris, smearing, and plastic flow on the surface of aluminium alloys. Smearing is a thin layer of plastic deformation that forms at the surface of the workpiece. It is often difficult to recognize and mainly occurs in materials with ductile natures [28]. The smearing in this instance appeared due to the rise in temperature because of increased $n$ and $f$. The random chip debris on some of the surfaces of the hole walls was also caused by the generation of material smearing [27]. Moreover, the deformation marks might be either due to the rubbing action of the chips that collided with the hole walls during evacuation [3]. The feed marks occurred as a result of an increase in feed. Furthermore, 
there were also chances of material side flow near the regions of feed marks where the plastically deformed material was ploughed aside due to the high thrust force and cutting temperature when the tool was used under dry cutting conditions [29]. Interestingly, no visible cracks were found on the surface under all cutting conditions. However, the damage and distortion in the hole of AA5083 were found more often than those seen in AA2024 and AA6061. A likely explanation for this might be the poor thermal conductivity of the work material, which enhances the heat accumulation in the primary deformation zone [30]. In addition, drilling at a higher $n$ and $f$ showed plastic flow within the hole walls of AA5083, which might also be due to its ductility and low silicon contents.

Figure 7 shows the top and bottom edges of the holes of all the alloys studied in this work. The results showed that the holes at both the top and bottom of the hole for all the three alloys (AA5083, AA6061, and AA2024) increased with an increase of $n$ and $f$. The results also showed that the hole edges of all the alloys were found to be more uniform around the edges, while the bottom sides had irregular appearances and heights. Therefore, the holes at the entrance were more deteriorated at the bottoms than the tops, except for AA5083, where most deterioration occurred at the lower $n$ and $f$. Other details can be found in Appendix A. Additionally, a detailed discussion of the results can be found in the succeeding section.
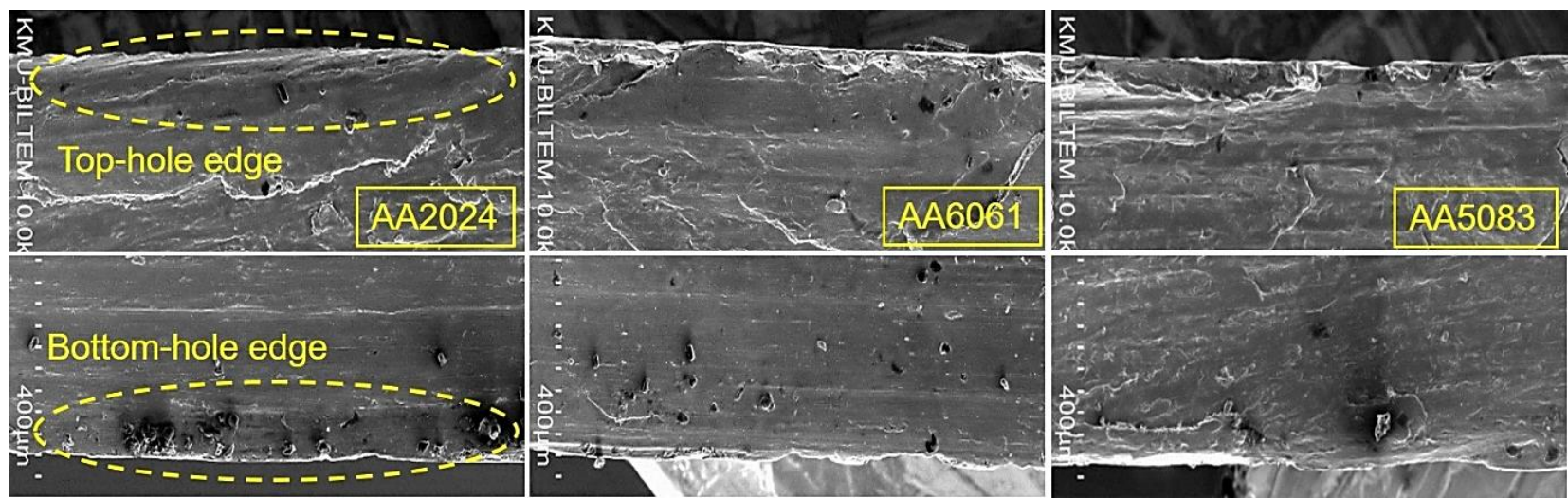

Figure 7. SEM of top- and bottom-hole edges drilled at $3025 \mathrm{rpm}$ and $0.14 \mathrm{~mm} / \mathrm{rev}$.

\section{Discussion}

Hole quality is assessed by factors such as cutting parameters, tool materials and coatings, tool geometry, the vibration of the drill, the chatter or drilling temperature, etc. [31]. Generally, in this study, the impact of $n$ was found more than $f$, especially in the case of deviation of hole size and cylindricity error. According to Kurt et al. [7], the deviation of hole size due to the high $n$ was expected due to the increase in the drilling vibration, which might impact hole geometrical features. Moreover, there were chances of increasing temperatures, especially at high spindle speeds, which could have influenced the hole accuracy and surface finish. However, it is worth noting that the ANOVA analysis indicated that the $n$ and alloy type and their interaction were significant on the hole size and circularity. Meanwhile, ANOVA results showed that both $n$ and $f$ did not have an impact on the hole perpendicularity, which means that different aluminium alloys will have different circularities under the same cutting parameters. Furthermore, other parameters which were not taken into account in this study could have a strong influence on perpendicularity, such as vibration, hole location, or machine dynamics [23]. Additionally, according to Uddin et al. [12], such variations could have resulted from errors in measurement by CMM, as even after cleaning the surface, there might be chances of debris potentially adhered to the surface that could have affected the measurement.

In addition to the drilling parameters, ease of machining was affected by the work material properties like hardness, tensile properties, chemical composition, microstructure, 
and work material production. Therefore, the above results showed that the surface finish of AA6061 was better than those obtained during the drilling of AA2024, following AA5083. This might be related to the high percentage composition of silicon in AA6061 compared with AA2024 and AA5083, as previous research concluded that a high silicon content might result in a good surface finish [32,33]. Furthermore, according to Köklü [34], the higher value of elongation is related to the amount of plastic deformation, which is governed by the ductility of the material. Therefore, it might also be possible that the highest percentage of elongation affected the surface finish of AA2024. Overall, the worst surface finish was generated in the drilling of AA5083, which was attributed to its low machinability and low silicon contents [16]. Furthermore, according to Ratnam [35], hardness is an essential characteristic of materials, affecting the surface finish, and it is worth noting that AA5083 has the lowest hardness compared to the two alloys. Hardness tends to form high built-up edges, and hence, a poor surface finish. Additionally, the above results indicated that the poor machinability and larger thermal coefficient of AA5083 compared to AA2024 and AA6061 caused the more oversized and irregular pattern that formed around the top and the bottom of the hole edges [16]. This finding also confirms our previous result where the surface roughness of AA6061 was found to be the lowest, following AA2024 and AA5083. Furthermore, the highest build-up edge was formed on the tools used for drilling of AA5083, due to long and thick chips tangled around the tools [16].

The above SEM image results also illustrated that the surface finish at the top region was affected more than at the bottom of the hole. This is also in agreement with Kurt et al. [7], who suggested that the vibration may have maximum values when the drill touches the workpiece. The spring back phenomenon can occur because of the workpiece material's elastic deformation during the drilling tool movement. However, in this study, most of the drilling parameters, including the hole surface finish at the bottom, were highly affected. This was because, as the drill reached its exit side, the material got plastically deformed [36]. Furthermore, some material was pushed out by the thrust force without being cut; thus, forming more burrs [37]. The different formation mechanism made the top and bottom surface finish differently from each other. The top region of the hole was affected due to tearing and a bending action, followed by clean shearing or lateral extrusion. In contrast, the thermal effect and plastic deformation of the materials made the bottom region more vulnerable to defects [38]. Therefore, the materials that did not sustain a small amount of plastic deformation were more prone to fracture in this region. Thus, it could be concluded that the surface defects were material properties-dependent [39]. The temperature may also have impacted the accuracy and surface finish since, according to Shanmughasundaram and Subramanian [40], the top region of the hole might have faced low temperature and thrust force.

\section{Conclusions}

This study investigated the hole dimensional tolerances and surface finish in AA2024, AA6061, and AA5083 under dry conditions during a multi-spindle simultaneous drilling process. The holes produced in these alloys were compared under the same drilling parameters and using the same drilling tools results from drilling tests. It was concluded from the investigations that AA2024 outperformed in hole quality by producing less circularity error, cylindricity error, and perpendicularity error, irrespective of the drilling parameters. Only in the case of hole size, the holes drilled in AA6061 were less deviated from the nominal size. This was followed by AA2024 and then AA5083. SEM examination revealed surface damage in the form of metal debris adhesion, smeared material, side flow, and feed marks. The worst surface finish and the most oversized and irregular patterns formed around the top and bottom of the hole edges generated in the drilling of AA5083 due to its low machinability, low hardness value, low silicon contents, and large coefficient of thermal expansion. The spindle speed was found to be more influential than feed and affected the hole size with a percentage contribution of $9.71 \%$ for hole size and $11.35 \%$ cylindricity error. The spindle speed and feed showed an insignificant effect on the 
circularity error and perpendicularity error; however, in general, a non-linear trend was observed in affecting the hole quality. These variations were expected due to the minute cutting debris potentially adhered to the surface that affected the CMM measurement. Furthermore, the machine drill vibration and temperature variations were not considered in this study and need further investigation during the multi-spindle drilling process.

Author Contributions: Conceptualization, M.A., and M.T.-R.; methodology, M.A., M.T.-R., and K.G.; validation, M.A., M.T.-R., K.G., A.V., U.K., and W.K.; investigation, M.A., K.G., U.K., and W.K.; writing—original draft preparation, M.A.; writing—review and editing, M.T.-R., K.G., U.K., and A.V. All authors have read and agreed to the published version of the manuscript.

Funding: This research received no external funding.

Institutional Review Board Statement: Not applicable.

Informed Consent Statement: Not applicable.

Data Availability Statement: The data presented in this study are available on request.

Acknowledgments: The first author would like to thank Edith Cowan University for the awarded (ECU-HDR) higher degree research scholarship.

Conflicts of Interest: The authors declare no conflict of interest.

\section{Appendix A}

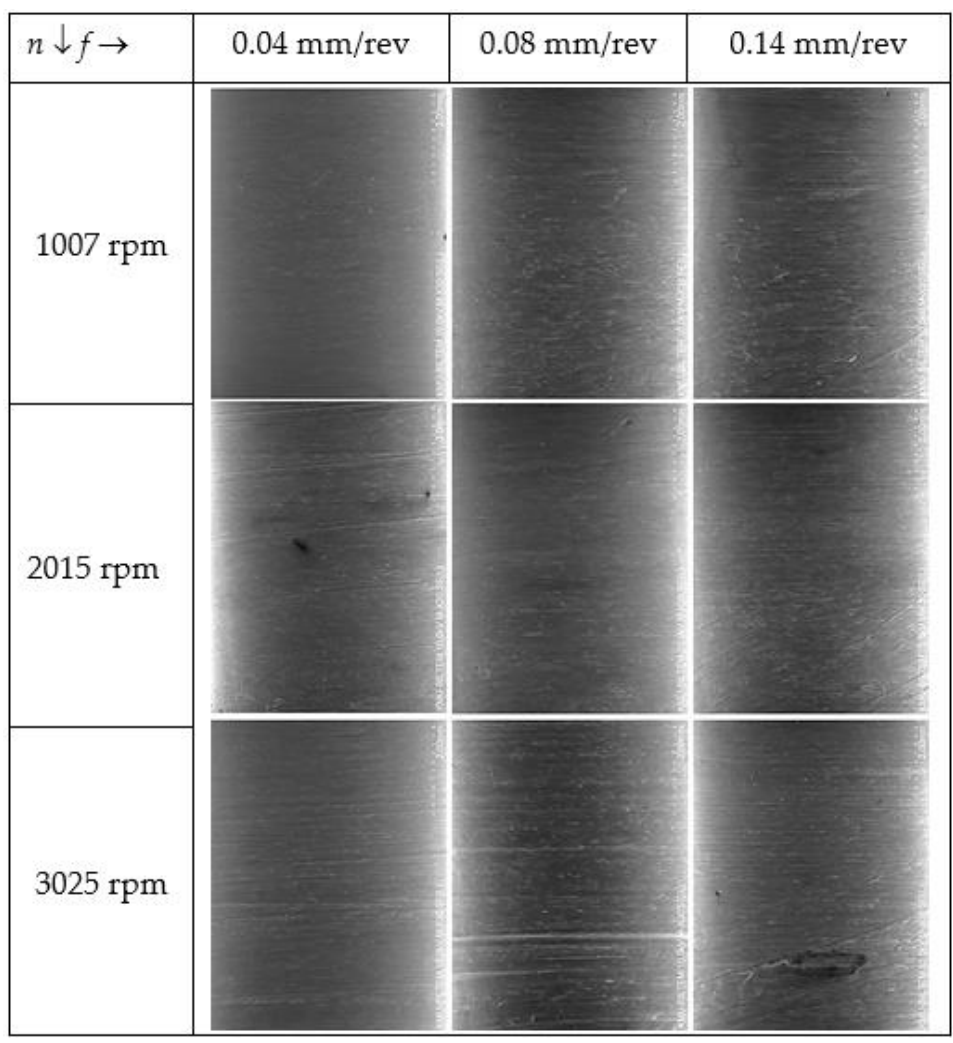

Figure A1. Hole images of AA2024. 


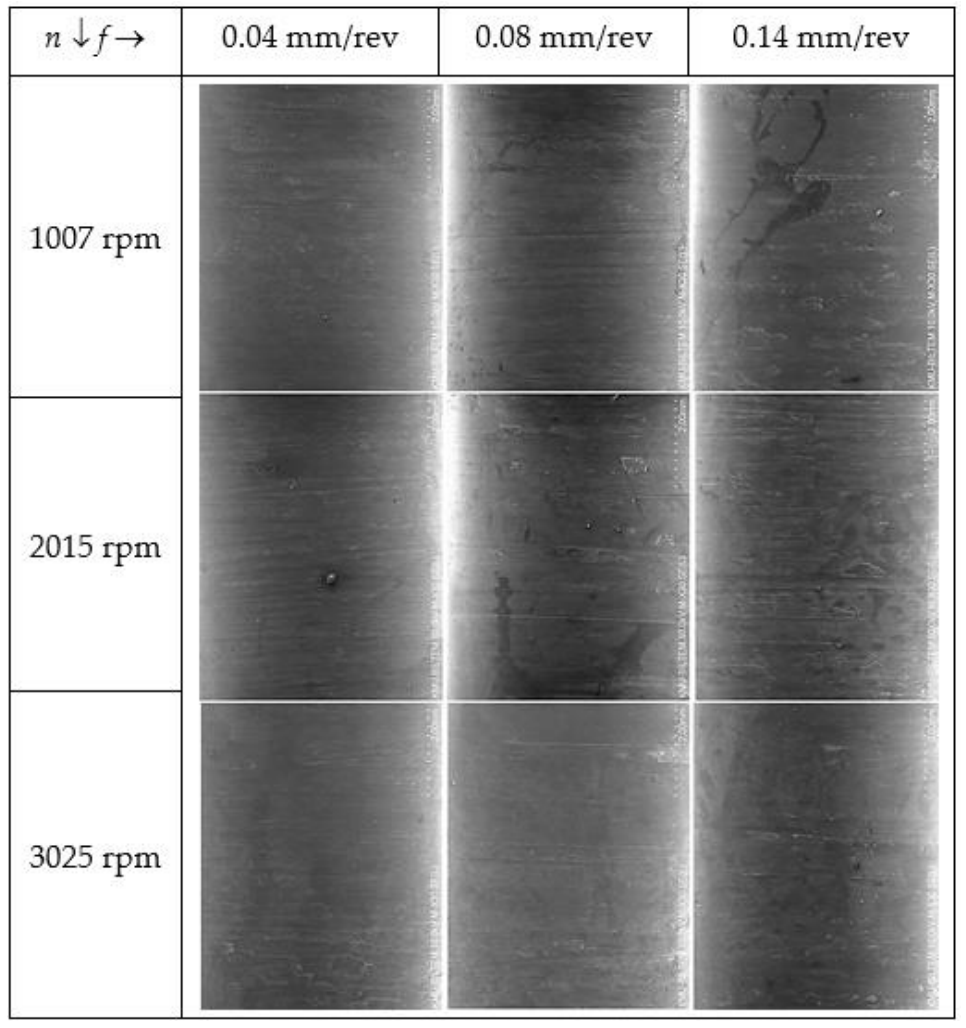

Figure A2. Hole images of AA6061.

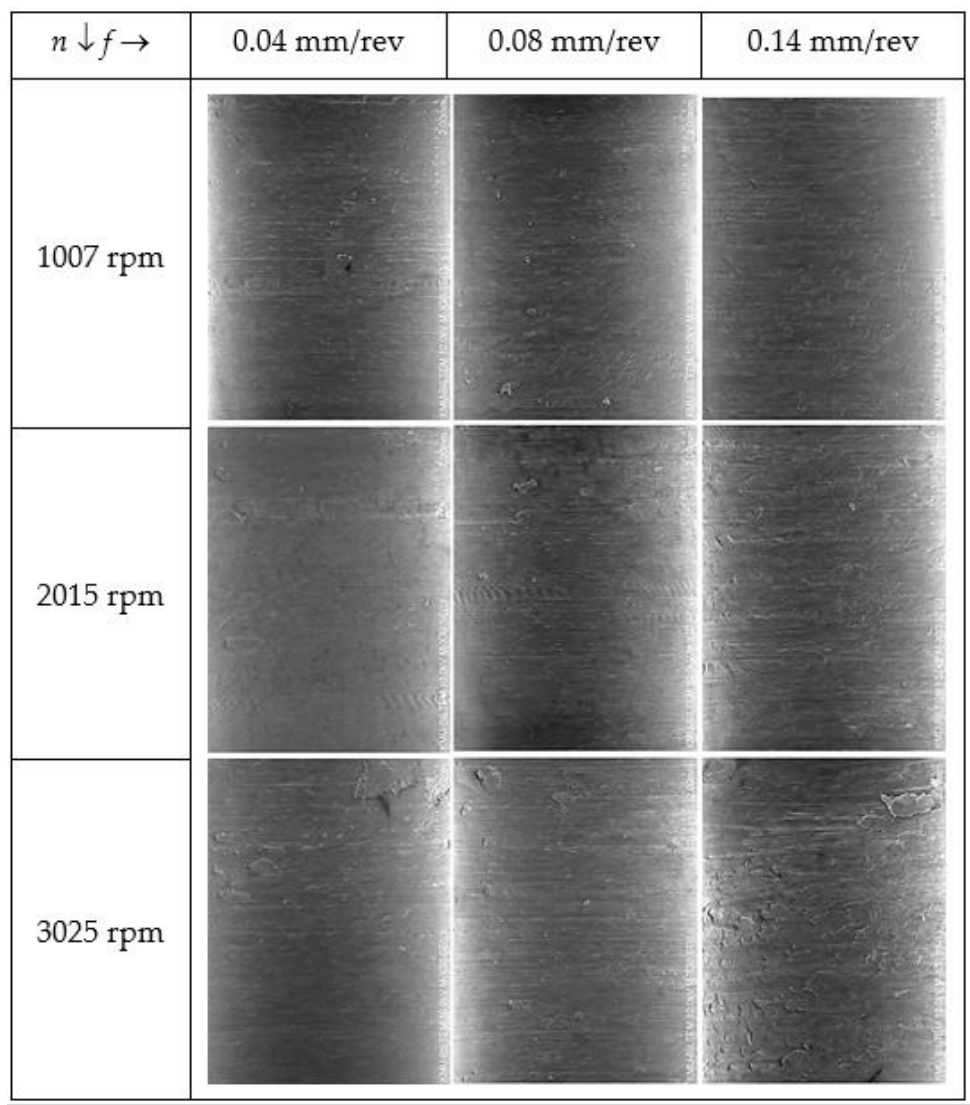

Figure A3. Hole images AA5083. 


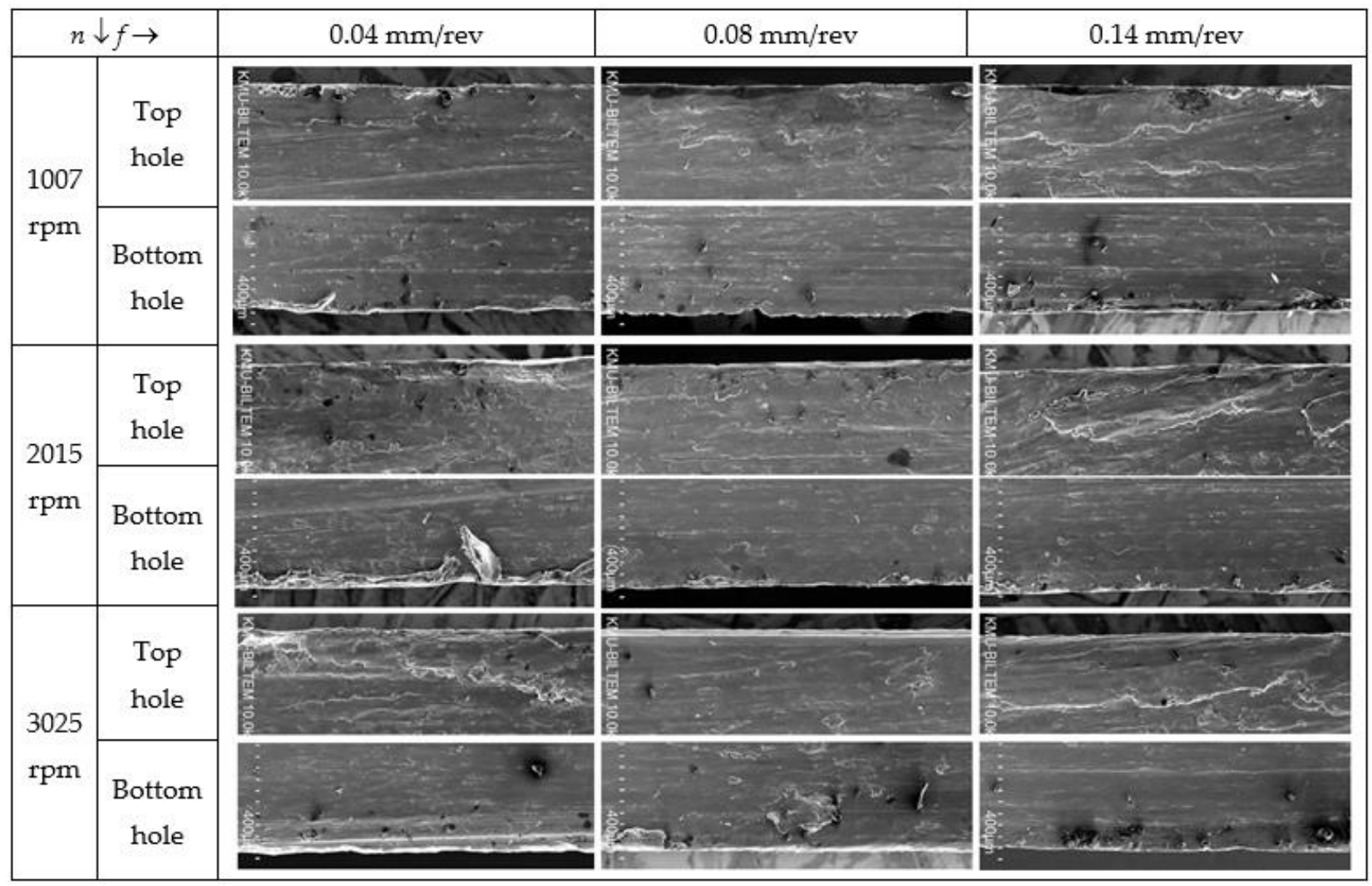

Figure A4. Top- and bottom-hole edges of AA2024.

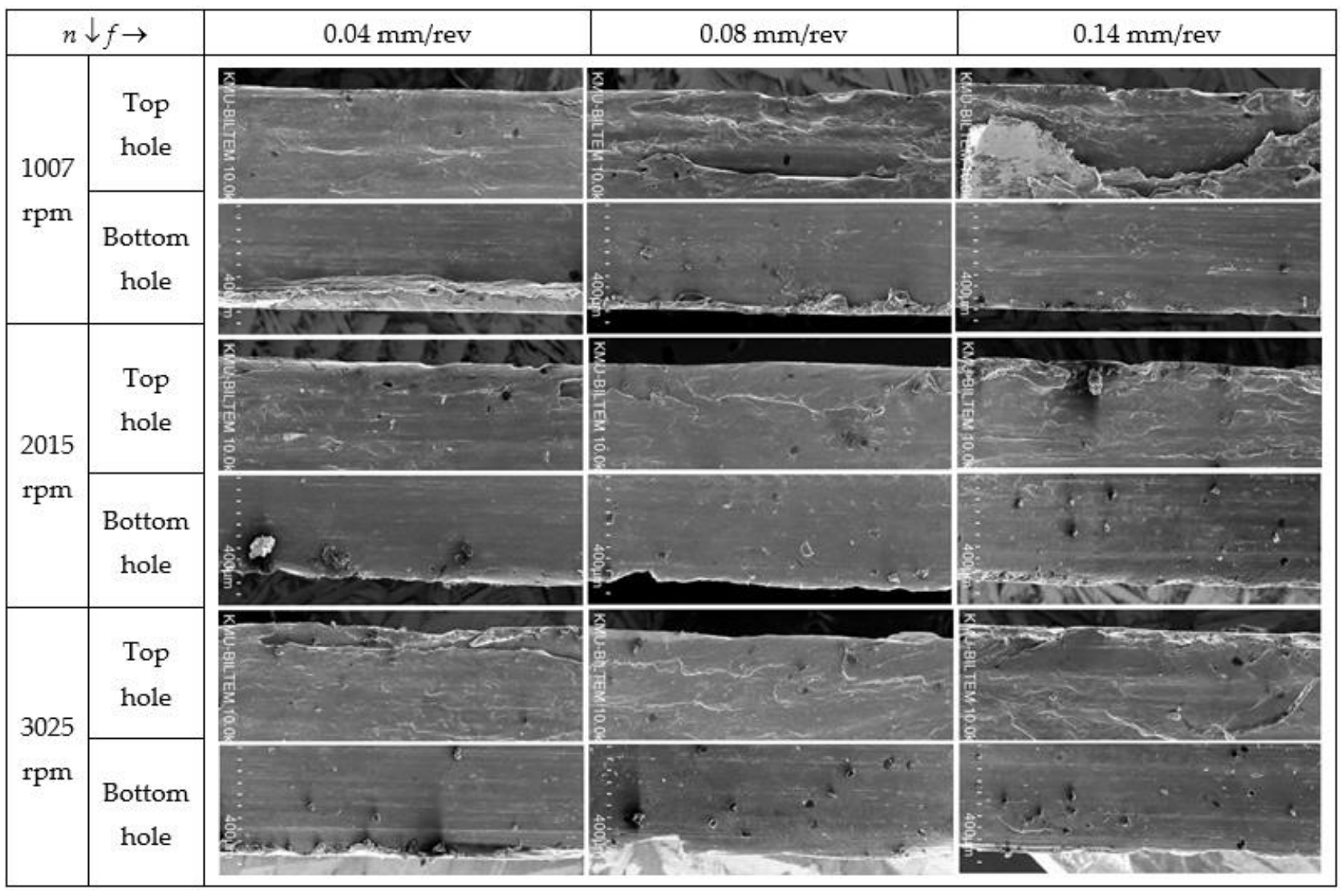

Figure A5. Top- and bottom-hole edges AA6061. 


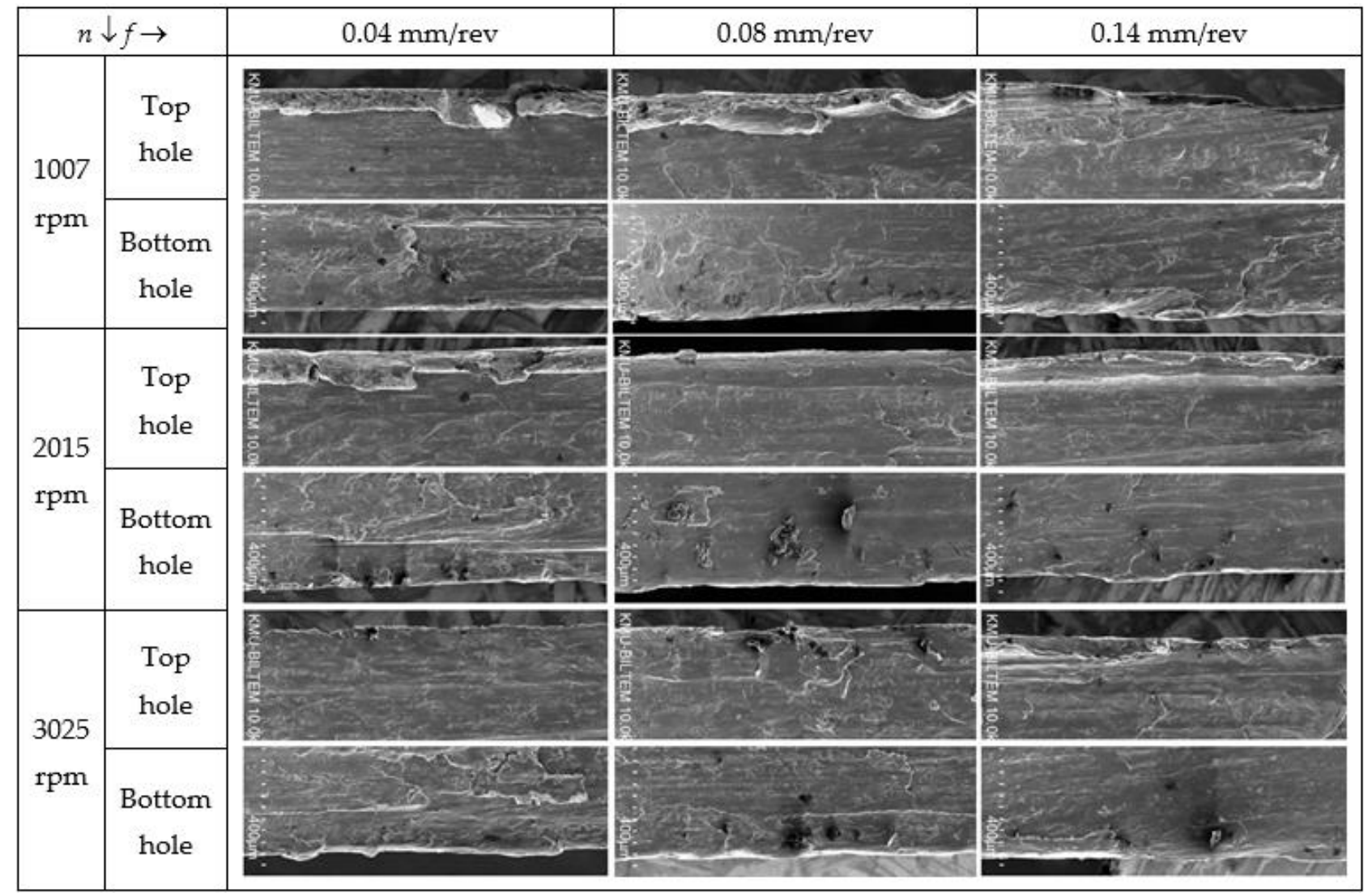

Figure A6. Top- and bottom-hole edges of AA5083.

\section{References}

1. Aamir, M.; Giasin, K.; Tolouei-Rad, M.; Vafadar, A. A review: Drilling performance and hole quality of aluminium alloys for aerospace applications. J. Mater. Res. Technol. 2020, 9, 12484-12500. [CrossRef]

2. Tolouei-Rad, M.; Aamir, M. Analysis of the Performance of Drilling Operations for Improving Productivity. In Drilling; ToloueiRad, M., Ed.; IntechOpen: London, UK, 2021. Available online: https://www.intechopen.com/online-first/analysis-of-theperformance-of-drilling-operations-for-improving-productivity (accessed on 9 May 2021).

3. Giasin, K.; Hawxwell, J.; Sinke, J.; Dhakal, H.; Köklü, U.; Brousseau, E. The effect of cutting tool coating on the form and dimensional errors of machined holes in GLARE ${ }^{\circledR}$ fibre metal laminates. Int. J. Adv. Manuf. Technol. 2020, 107, $2817-2832$. [CrossRef]

4. Aamir, M.; Tolouei-Rad, M.; Giasin, K.; Nosrati, A. Recent advances in drilling of carbon fiber-reinforced polymers for aerospace applications: A review. Int. J. Adv. Manuf. Technol. 2019, 105, 2289-2308. [CrossRef]

5. Giasin, K.; Gorey, G.; Byrne, C.; Sinke, J.; Brousseau, E. Effect of machining parameters and cutting tool coating on hole quality in dry drilling of fibre metal laminates. Compos. Struct. 2019, 212, 159-174. [CrossRef]

6. Giasin, K. The effect of drilling parameters, cooling technology, and fiber orientation on hole perpendicularity error in fiber metal laminates. Int. J. Adv. Manuf. Technol. 2018, 97, 4081-4099. [CrossRef]

7. Kurt, M.; Kaynak, Y.; Bagci, E. Evaluation of drilled hole quality in Al 2024 alloy. Int. J. Adv. Manuf. Technol. 2008, 37, 1051-1060. [CrossRef]

8. Leep, H.R. Influence of cutting fluids on surface finish of holes drilled into aluminium 390. J. Synth. Lubr. 1990, 6, 325-338. [CrossRef]

9. Bono, M.J. Experimental and Analytical Issues in Drilling; University of Michigan: Ann Arbor, MI, USA, 2003.

10. Kurt, M.; Bagci, E.; Kaynak, Y. Application of Taguchi methods in the optimization of cutting parameters for surface finish and hole diameter accuracy in dry drilling processes. Int. J. Adv. Manuf. Technol. 2009, 40, 458-469. [CrossRef]

11. Kushnoore, S.; Noel, D.; Kamitkar, N.; Satishkumar, M. Experimental investigations on thrust, torque and circularity error in drilling of aluminium alloy (Al6061). Am. J. Mech. Ind. Eng. 2016, 1, 96-102.

12. Uddin, M.; Basak, A.; Pramanik, A.; Singh, S.; Krolczyk, G.M.; Prakash, C. Evaluating hole quality in drilling of Al 6061 alloys. Materials 2018, 11, 2443. [CrossRef]

13. Islam, M.N.; Boswell, B. Effect of cooling methods on hole quality in drilling of aluminium 6061-6T. In Proceedings of the IOP Conference Series: Materials Science and Engineering, Kuala Lumpur, Malaysia, 12-14 November 2015; p. 012022. 
14. Nouari, M.; List, G.; Girot, F.; Coupard, D. Experimental analysis and optimisation of tool wear in dry machining of aluminium alloys. Wear 2003, 255, 1359-1368. [CrossRef]

15. Aamir, M.; Tolouei-Rad, M.; Giasin, K. Multi-spindle drilling of Al2024 alloy and the effect of TiAlN and TiSiN-coated carbide drills for productivity improvement. Int. J. Adv. Manuf. Technol. 2021, 1-10.

16. Aamir, M.; Tolouei-Rad, M.; Giasin, K.; Vafadar, A. Machinability of Al2024, Al6061, and Al5083 alloys using multi-hole simultaneous drilling approach. J. Mater. Res. Technol. 2020, 9, 10991-11002. [CrossRef]

17. Aamir, M.; Tu, S.; Giasin, K.; Tolouei-Rad, M. Multi-hole simultaneous drilling of aluminium alloy: A preliminary study and evaluation against one-shot drilling process. J. Mater. Res. Technol. 2020, 9, 3994-4006. [CrossRef]

18. Aamir, M.; Tu, S.; Tolouei-Rad, M.; Giasin, K.; Vafadar, A. Optimization and modeling of process parameters in multi-hole simultaneous drilling using taguchi method and fuzzy logic approach. Materials 2020, 13, 680. [CrossRef] [PubMed]

19. Aamir, M.; Tolouei-Rad, M.; Giasin, K.; Vafadar, A. Feasibility of tool configuration and the effect of tool material, and tool geometry in multi-hole simultaneous drilling of Al2024. Int. J. Adv. Manuf. Technol. 2020, 111, 861-879. [CrossRef]

20. Aamir, M.; Tolouei-Rad, M.; Vafadar, A.; Raja, M.N.A.; Giasin, K. Performance Analysis of Multi-Spindle Drilling of Al2024 with TiN and TiCN Coated Drills Using Experimental and Artificial Neural Networks Technique. Appl. Sci. 2020, 10, 8633. [CrossRef]

21. Batzer, S.; Haan, D.; Rao, P.; Olson, W.; Sutherland, J. Chip morphology and hole surface texture in the drilling of cast aluminum alloys. J. Mater. Process. Technol. 1998, 79, 72-78. [CrossRef]

22. Sreejith, P.; Ngoi, B. Dry machining: Machining of the future. J. Mater. Process. Technol. 2000, 101, 287-291. [CrossRef]

23. Giasin, K.; Ayvar-Soberanis, S.; French, T.; Phadnis, V. 3D Finite Element Modelling of Cutting Forces in Drilling Fibre Metal Laminates and Experimental Hole Quality Analysis. Appl. Compos. Mater. 2017, 24, 113-137. [CrossRef]

24. Al-Tameemi, H.A.; Al-Dulaimi, T.; Awe, M.O.; Sharma, S.; Pimenov, D.Y.; Koklu, U.; Giasin, K. Evaluation of Cutting-Tool Coating on the Surface Roughness and Hole Dimensional Tolerances during Drilling of Al6061-T651 Alloy. Materials 2021, 14, 1783. [CrossRef]

25. Giasin, K.; Hodzic, A.; Phadnis, V.; Ayvar-Soberanis, S. Assessment of cutting forces and hole quality in drilling Al2024 aluminium alloy: Experimental and finite element study. Int. J. Adv. Manuf. Technol. 2016, 87, 2041-2061. [CrossRef]

26. Poznak, A.; Freiberg, D.; Sanders, P. Chapter 10-Automotive Wrought Aluminium Alloys. In Fundamentals of Aluminium Metallurgy; Lumley, R.N., Ed.; Woodhead Publishing: Sawston, UK, 2018; pp. 333-386.

27. Liang, X.; Liu, Z.; Wang, B. State-of-the-art of surface integrity induced by tool wear effects in machining process of titanium and nickel alloys: A review. Measurement 2019, 132, 150-181. [CrossRef]

28. Buehler. Solutions for Materials Preparation, Testing \& Analysis: Don't Smear It! Avoiding Surface Deformation in Polishing. Available online: https:/ / metallography-matters.buehler.com/2018/09/17/dont-smear-it-avoiding-surface-deformation-inpolishing/\#: \{\{\}:text=To\%20prevent $\% 20$ smearing $\% 2 \mathrm{C} \% 20$ it $\backslash \mathrm{T} 1 \backslash$ textquoterights $\% 20$ best,polishing $\% 20$ surface $\% 20 \mathrm{can} \% 20$ also $\%$ 20help (accessed on 6 March 2021).

29. Kishawy, H.; Elbestawi, M. Effects of process parameters on material side flow during hard turning. Int. J. Mach. Tools Manuf. 1999, 39, 1017-1030. [CrossRef]

30. Pawade, R.; Joshi, S.S.; Brahmankar, P.; Rahman, M. An investigation of cutting forces and surface damage in high-speed turning of Inconel 718. J. Mater. Process. Technol. 2007, 192, 139-146. [CrossRef]

31. Roukema, J.C.; Altintas, Y. Generalized modeling of drilling vibrations. Part II: Chatter stability in frequency domain. Int. J. Mach Tools Manuf. 2007, 47, 1474-1485. [CrossRef]

32. Akyüz, B. Effect of silicon content on machinability of AL-SI alloys. Adv. Sci. Technol. Res. J. 2016, 10, 51-57. [CrossRef]

33. Kamiya, M.; Yakou, T.; Sasaki, T.; Nagatsuma, Y. Effect of Si content on turning machinability of Al-Si binary alloy castings. Mater. Trans. 2008, 49, 587-592. [CrossRef]

34. Köklü, U. Influence of the process parameters and the mechanical properties of aluminum alloys on the burr height and the surface roughness in dry drilling. Mater. Tehnol. 2012, 46, 103-108.

35. Ratnam, M. Factors affecting surface roughness in finish turning. In Comprehensive Materials Finishing; Elsevier: Amsterdam, The Netherlands, 2017; Volume 1, pp. 1-25.

36. Ko, S.-L.; Lee, J.-K. Analysis of burr formation in drilling with a new-concept drill. J. Mater. Process. Technol. 2001, 113, 392-398. [CrossRef]

37. Choudhury, I.A.; Lawal, S.A. 11.12-Burr Formation in Machining Processes: A Review. In Comprehensive Materials Processing; Elsevier: Oxford, UK, 2014; Volume 11, pp. 283-295.

38. Zhu, Z.; Guo, K.; Sun, J.; Li, J.; Liu, Y.; Zheng, Y.; Chen, L. Evaluation of novel tool geometries in dry drilling aluminium 2024-T351/titanium Ti6Al4V stack. J. Mater. Process. Technol. 2018, 259, 270-281. [CrossRef]

39. Mann, J.Y.; Milligan, I.S. Aircraft Fatigue: Design, Operational and Economic Aspects; Elsevier Science: Melbourne, Australia, 2013.

40. Shanmughasundaram, P.; Subramanian, R. Study of parametric optimization of burr formation in step drilling of eutectic Al-Si alloy-Gr composites. J. Mater. Res. Technol. 2014, 3, 150-157. [CrossRef] 